\title{
РОЛЬ ПРОЕКТНОГО ПОДХОДА К РЕАЛИЗАЦИИ СТРАТЕГИЧЕСКОГО РАЗВИТИЯ АПК С УЧЕТОМ АНАЛИЗА ЭВОЛЮЦИИ ПРОЕКТНОГО УПРАВЛЕНИЯ
}

Проектное управление как способ организачии бизнес-прочессов на разных уровнях хозяйствования позволяет суцественно повысить эффективность стратегического управления. Однако одной из ключевых проблем реализации проектного управления в российской экономике является непонимание или неполное понимание внутренних особенностей проектного подхода, а само управление сводится к внедрению в практику отдельных его элементов. В статье изложена авторская точка зрения на формирование концепции стратегического развития агропромышиенного комплекса, основанная на результатах изучения эволючионно-генетических прочессов формирования проектного управления с использованием системно-иерархического анализа.

Ключевые слова: агропромыиленный комплекс, проектное управление, стратегия развития, эволючия проектного подхода.

\section{Andrej Gurinov \\ THE PROJECT APPROACH OF STRATEGIC OF AGRICULTURE TAKING INTO ACCOUNT THE ANALYSIS OF THE EVOLUTION OF PROJECT MANAGEMENT}

Project management as a way of organizing business processes at different levels of management can significantly improve the effectiveness of strategic management. However, one of the key problems in the implementation of project management in the Russian economy is a misunderstanding or incomplete understanding of the internal features of the project approach, and the management itself is reduced to implementation in practice. its individual elements. The article presents the author's view on the formation of the strategic growth concept for the agricultural industry, which is based upon the results of a study on evolutionary-genetic processes on the formation of project management by using the system-hierarchy analysis.

Key words: agro-industry complex, project management, strategy of development, evolution of the project approach.

Bведение / Introduction. Развитие агропромышленного комплекса, являющегося одним из элементов, формирующих социально-экономическую основу государства, относится к приоритетным направлениям экономического развития Российской Федерации, о чем неоднократно заявлялось на самом высоком уровне. В экономически развитых странах АПК является одним из драйверов национальных экономик, что обусловливает необходимость выработки и реализации целого комплекса мероприятий, направленных на развитие и устойчивость данного сегмента государственной экономики. Агропромышленный комплекс, по сути, представляет собой совокупность нескольких отраслей национальной хозяйственной системы, ориентированных на производство и переработку сельскохозяйственной продукции с различной степенью добавленной стоимости. Важной особенностью продукции АПК является ее высокий потенциал для дальнейшей переработки, что вовлекает в орбиту АПК множество подотраслей и смежных секторов экономики (транспорт, логистика, маркетинг, химическое производство и т. д.).

Материалы и методы / Materials and methods. Функционирование АПК также рассматривается как важное условие защиты интересов государства и в социальном, и в экономическом аспектах. 
Развитие экономики страны в целом характеризует один из наиболее информативных показателей - валовой внутренний продукт (ВВП) (рис. 1).

Несмотря на функционирование страны в условиях санкционного давления с 2014 г., объем ВВП продолжает расти.

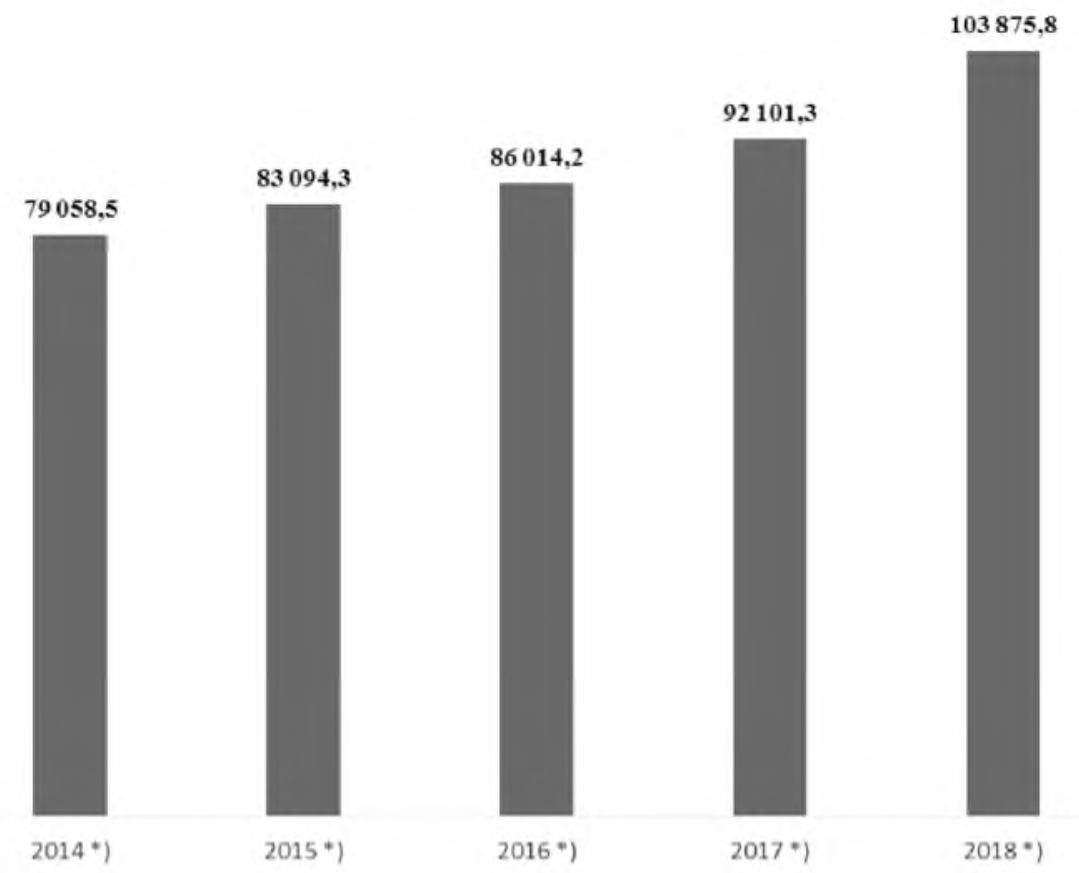

Рис. 1. Динамика ВВП России в 2014-2018 гг,, млрд руб. (в текуших ценах) *(рассчитано по данным Росстата [15]

Вклад основной отрасли агропромышленного комплекса - сельского хозяйства - в формирование ВВП, характеризуют данные, приведенные на рис. 2.

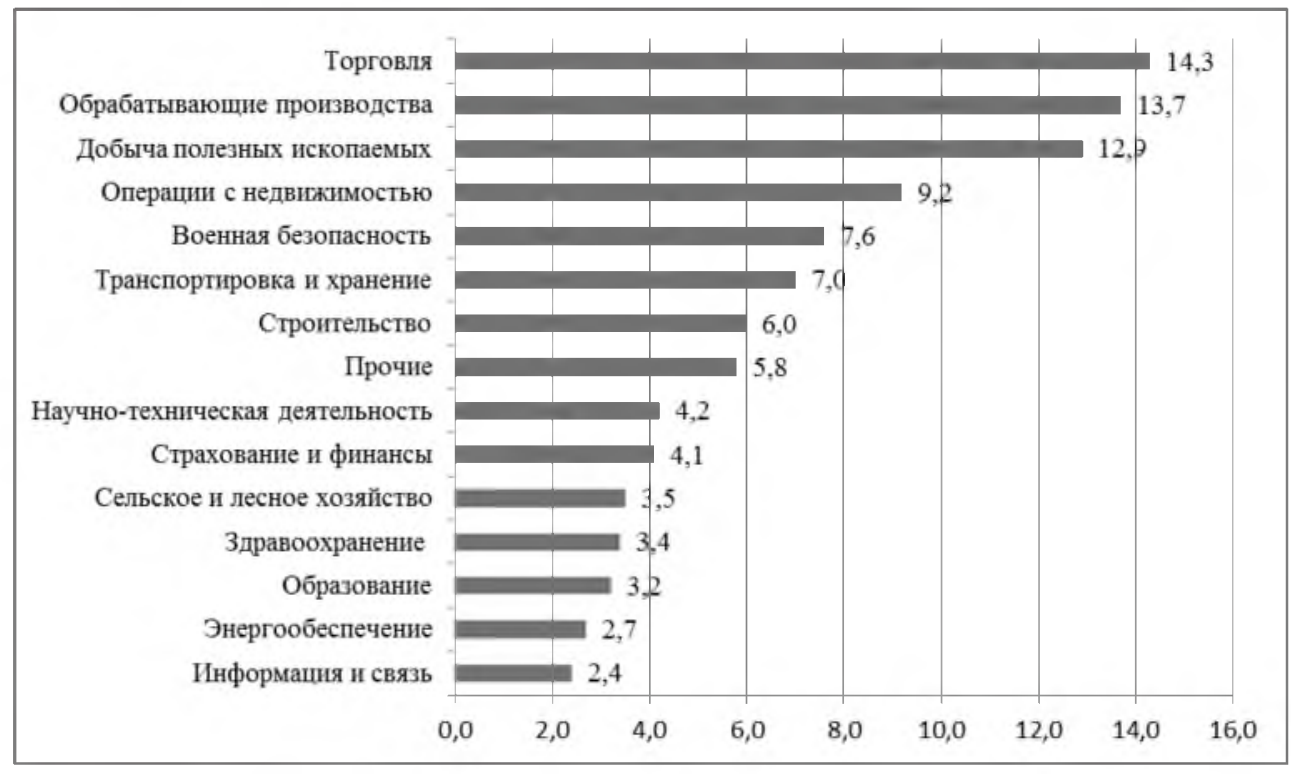

Рис. 2. Ранжирование отраслей экономики России по величине доли в ВВП в 2018 г. (рассчитано по данным Росстата [16] 
Несмотря на важное значение отрасли, ее доля в российской экономике невысока. Удельный вес отечественного агропромышленного производства в мировом объеме продукции, произведенной в АПК, также небольшой. Мировой показатель объема продукции агропромышленного комплекса превысил 6 трлн долл. США, а доля российского АПК с объемом производства порядка 80 млрд долл. составляет около 1,3\% [17]. В связи с этим перед отечественным агропромышленным производством стоит непростая и амбициозная задача по обеспечению устойчивого роста, что особенно актуально на фоне прогнозов в части развития ситуации на глобальном сельскохозяйственном рынке. Согласно аналитическим данным ФАО и ОЭСР, в ближайшей и среднесрочной перспективе ожидается:

- интенсификация роста спроса на продовольствие;

- рост объемов потребления животноводческой продукции;

- повышение рисков долгосрочного характера в части нестабильности мировых рынков агропродовольственной направленности.

Согласно прогнозам, рост численности населения и ожидаемое повышение доходов на период до 2050 г. обусловят рост спроса и необходимость увеличения объема глобального производства продукции АПК до 70 \% в сравнении со значением показателя по состоянию на начало XXI в. [11]. При этом высказываются опасения по поводу того, что темпы среднегодовых приростов объьемов производства в сфере АПК будут не такими высокими, как в сфере потребления, в случае если не произойдут качественные изменения в подходах к организации производства и не будет принято управленческих решений инновационного характера, способных переломить существующие тенденции [5].

Кроме того, актуальной поблемой развития агропромышленного производства на мировом уровне является проблема накопления регрессивного экологического потенциала, обусловленного развитием промышленного производства, неравномерностью распределения производственных мощностей в региональном разрезе, ростом выбросов отходов производства и другими негативными факторами [12].

Указанное выше формирует понимание необходимости разработки и внедрения инструментов и механизмов, способных оказать позитивное влияние на эффективность функционирования национального АПК, что, в свою очередь, ставит задачу разработки новых и повышения влияния существующих подходов, способствующих интенсификации агропромышленного производства на национальном уровне в целях:

1) недопушения отставания в темпах развития национального АПК от АПК развитых государств;

2) обеспечения устойчивого и прогнозируемого роста АПК, что подразумевает сохранение потенциала такого роста в долгосрочной перспективе;

3) выхода отечественного АПК на качественно новый уровень, обеспечивающий достаточную конкурентоспособность комплекса и национальную продовольственную безопасность.

Большинство аналитических источников, специализирующихся на исследовании российской экономики в целом и АПК в частности, указывает на следующие драйверы роста исследуемой отрасли в части повышения ее конкурентоспособности $[4,8]$ :

- эффективность государственной поддержки

- стабильность государственной политики в сфере законодательства и регулятивного функционала

- сдерживание роста стоимости энергетических ресурсов.

Соответственно, в числе основных проблем развития АПК определены:

1) высокая стоимость ресурсов, в т. ч. энергетических;

2) недостаточный объем государственной поддержки и финансирования

3) нехватка квалифицированных кадров [12]. 
Очевидно, что в представленный перечень наиболее весомых факторов, детерминирующих эффективность функционирования АПК, вошли факторы внешнего характера [6]. Однако такой подход, на наш взгляд, делает этот список недостаточно полным и точным. Несомненно, показатели ресурсного обеспечения оказывают сильнейшее влияние на эффективность отраслевого функционирования. Однако не менее важным фактором является внутренняя среда, состояние которой во многом зависит от качества управления.

Среди современных управленческих инструментов выделяется проектный подход, приобретающий все большее значение во многих сферах деятельности. Понимание историко-генетических основ его формирования и эволюции поможет выявить его ключевые преимущества и недостатки, особенности использования, а также экстраполировать существующий опыт применения проектного управления на реалии современной экономической ситуации в российской экономике в целом, а также в отдельных отраслях в частности [1].

Деятельность, которая сегодня называется управленческой, велась человечеством с самых ранних времен. Однако систематизация управленческих решений наиболее ярко стала проявляться в следующих аспектах человеческой деятельности [2]:

- социальном - в процессе выделения лидеров среди социальных групп (племен, кланов, семей и т. д.) и выработке ими решений, предполагающих постановку целей, определение задач, распределение функционала и другие элементы современного проектного управления;

- военном - принятие решений о начале или окончании ведения военных действий, выработка военно-политической стратегии и тактики и т. д.;

- $\quad$ экономическом - наиболее информативным примером реализации проектного подхода стали гигантские стройки в государствах античного мира: Древнем Египте, Древней Греции др. В целом эволюционно-генетический процесс формирования проектного подхода можно отобразить следующим образом (рис. 3).

Пониманию сущности и особенностей проектного подхода способствует анализ управления как самостоятельного и полноценного направления деятельности, в рамках которого следует выделить следующие этапы развития управленческой мысли $[3,10,2]$.

1. Административное управление (снижение производственных издержек, конец 19 - начало 20 в.)

- фактор конкуренции;

- формирование вертикально организованных структур.

2. Целевое управление (управление по конечным результатам, снижение упущенной выгоды):

- повышение качества продукции;

- внедрение высоких стандартов обслуживания заказчиков;

- $\quad$ упор на производство продукции, удовлетворяющей спрос;

- повышение роли маркетинга и рекламы;

- развитие горизонтальных связей в производстве.

3. Цифровизация управления (управление обучением, переход к метамотивации):

- глобализация рынков;

- усиление конкуренции;

- девиация условий бизнеса.

В настоящее время проектное управление реализуется в том или ином виде практически во всех сферах человеческой деятельности, однако наибольшее развитие он получил в экономической сфере, в наибольшей степени подверженной стремлениям к получению конкретного, измеримого и прогнозируемого результата. Во многом это обусловлено ключевыми преимуществами, которые делают проектное управление одним из условий успешной деятельности в долгосрочном измерении. Хотя следует признать и наличие определенных сложностей, которые неизбежны в случае реализации проектного подхода в управлении [9] (см. таблицу). 


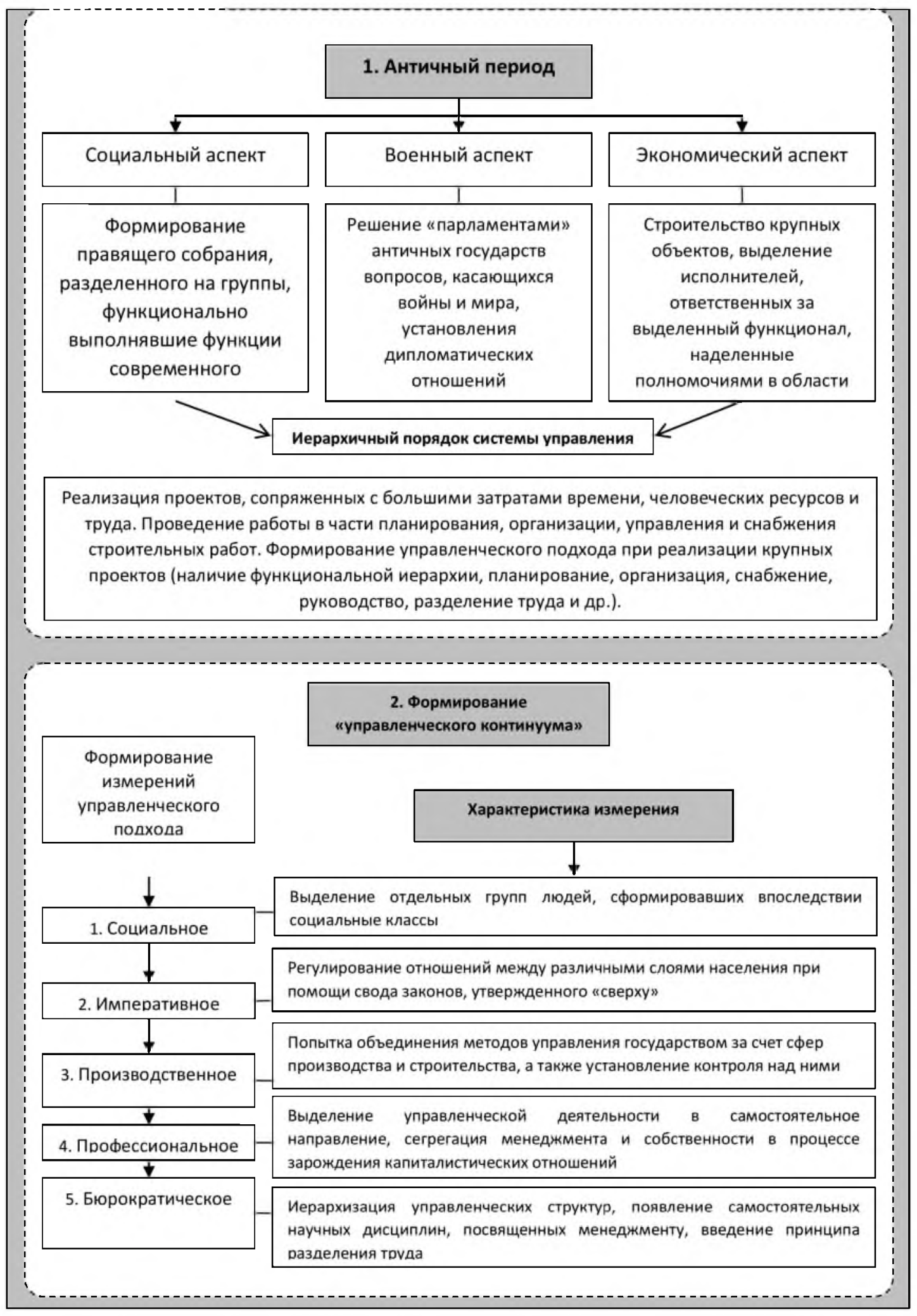

Рис. 3. Структуризация эволюционно-генетического процесса формирования проектного подхода 
Ключевые преимущества и недостатки проектного подхода

\begin{tabular}{|c|c|}
\hline Преимущество & Недостаток \\
\hline $\begin{array}{l}\text { Повышение эффективности процессов на подготови- } \\
\text { тельной стадии проекта за счет снижения сроков его } \\
\text { внедрения и совокупного снижения издержек }\end{array}$ & $\begin{array}{l}\text { Высокие требования к качеству проектных ра- } \\
\text { бот, необходимость поиска квалифицированных } \\
\text { проектных менеджеров }\end{array}$ \\
\hline $\begin{array}{l}\text { Снижение уровня проектных рисков за счет разра- } \\
\text { ботки дорожной карты проекта и анализа источников } \\
\text { финансирования }\end{array}$ & $\begin{array}{l}\text { Удорожание проекта на первых стадиях за счет } \\
\text { привлечения «дорогих» специалистов }\end{array}$ \\
\hline $\begin{array}{l}\text { Повышение эффективности использования ресурсов } \\
\text { проекта за счет планирования ресурсного потенциала }\end{array}$ & $\begin{array}{l}\text { Вероятность некачественных проектных работ, } \\
\text { что может повысить риски проекта }\end{array}$ \\
\hline $\begin{array}{l}\text { Возможность экстраполяции успешного опыта на } \\
\text { аналогичные проекты и масштабирования }\end{array}$ & $\begin{array}{l}\text { Рост зависимости проекта от качества анализи- } \\
\text { руемой информации }\end{array}$ \\
\hline $\begin{array}{l}\text { Снижение репутационных рисков и рост авторитета } \\
\text { компании, реализующей проект }\end{array}$ & $\begin{array}{l}\text { Возможность затягивания срока начала реа- } \\
\text { лизации проекта из-за отсутствия или замены } \\
\text { проектных специалистов }\end{array}$ \\
\hline \multicolumn{2}{|l|}{$\begin{array}{l}\text { Снижение интегрального риска проекта за счет карты } \\
\text { рисков, составленной в ходе его планирования }\end{array}$} \\
\hline \multicolumn{2}{|l|}{$\begin{array}{l}\text { Возможность избегания ошибок, допущенных в теку- } \\
\text { щем проекте, на стадии планирования аналогичных } \\
\text { проектов в будущем }\end{array}$} \\
\hline \multicolumn{2}{|l|}{$\begin{array}{l}\text { Повышение возможностей для проектного финанси- } \\
\text { рования из внешних источников за счет обеспечения } \\
\text { транспарентности проекта }\end{array}$} \\
\hline $\begin{array}{l}\text { Обеспечение гибкости проекта за счет разработки } \\
\text { стратегии его реализации, ее анализа и возможности } \\
\text { изменения целевых параметров и инструментария. }\end{array}$ & \\
\hline
\end{tabular}

Результаты и обсуждение / Results and discussion. По результатам исследования исторических и эволюционных основ зарождения и развития проектного подхода на различных этапах функционирования мировой экономики сделаны определенные выводы.

1. Проектная деятельность своими корнями уходит в далекое прошлое, однако принципы формирования проектного подхода остались во многом неизменными.

2. Наибольшее развитие проектный подход получил в экономической сфере, где наблюдается наибольшее стремление к получению измеримого результата (эффекта) и большой объем исследований в этой области дает ощутимые результаты, обеспечивая генезис проектной мысли.

3. Сам по себе проектный подход как методика не дает гарантий успешной реализации задач и достижения намеченных целей. Однако использование проектного подхода дает дополнительные возможности при планировании проектов в части повышения их транспаретности и возможности управления рисками.

Заключение / Conclusion. В заключение следует отметить, что реализация комплекса исследовательских мер в разрез ретроспективного, функционального и компаративного подходов позволяет объективно оценить сильные и слабые стороны проектного управления, а также реализовать внедрение проектного подхода в практику экономической деятельности открывает новые возможности при условии строгого соблюдения повышенных требований к данному методу. 


\section{ЛИТЕРАТУРА И ИНТЕРНЕТ-РЕСУРСЫ}

1. Алиева, Д. М. Реализация проектного подхода в государственном управлении АПК / Д. М. Алиева // Научно-техническое обеспечение агропромышленного комплекса в реализации Государственной программы развития сельского хозяйства до 2020 года : материалы Международной научно-практической конференции, посвященной 75 -летию Курганской ГСХА имени Т. С. Мальцева. - Саратов. 2019. - С. 155-158. - Текст : непосредственный.

2. Братченко, С. А. Формирование фундаментальных управленческих идей в период становления капитализма краткий обзор научных работ / С. А. Братченко // Управленческие науки. - 2018. - Т. 8. № 1. - С. 110-118. - Текст : непосредственный.

3. Громов, А. И. и др. Управление бизнес-процессами: современные методы: коллективная монография / А. И. Громов [и др.]. - Москва : Юрайт, 2017. 368 с. - Текст : непосредственный.

4. Гурьянова, Н. М. и др. Проблемы и основные направления повышения эффективности функционирования АПК региона в условиях глобализации и импортозамещения / Н. М. Гурьянова и др. ; под ред. О. А. Столяровой. - Пенза : РИО ПГАУ, 2018. - 236 с. - Текст : непосредственный.

5. Дибиров, А. А. Потенциал интеграции стран ЕАЭС в сфере продовольственного обеспечения населения / А. А. Дибиров, Е. С. Воуба // Экономика нового мира. - 2017. - № 4 (8). - С. 26-36. - Текст : непосредственный.

6. Лясников, Н. В. Агропромышленный комплекс России и необходимость обеспечения продовольственной безопасности в условиях международных санкций / Н. В. Лясников // Проблемы рыночной экономики. - 2018. - № 2. - С. 19-25. - Текст : непосредственный.

7. Найденова, Н. В. Экономические факторы ограничения роста российской экономики / Н. В. Найденова // Вестник СГЮА. - 2017. - № 1 (114). - С. 231-238. - Текст : непосредственный.

8. Султыгова, М. Б. Формирование ключевых детерминантов в системе экономической безопасности / М. Б Султыгова. // Вестник евразийской науки. - 2018. - Т. 10. - № 3. - С. 39. - Текст : непосредственный.

9. Чижова Е. Н., Медведев И. П. История управленческой мысли / Е. Н. Чижова, И. П. Медведев. - Белгород : Изд-во БГТУ, 2018. - 401 с. - Текст : непосредственный.

10. Жученко А. А. Средоулучшающие технологии в XXI веке / А. А. Жученко // Вестник Орловского государственного аграрного университета. - 2017. - № 3 (66). - С. 16-26. - Текст : непосредственный.

11. Проблемы и перспективы повышения эффективности функционирования свеклосахарного подкомплекса АПК / под ред. Г. Г. Лалаян, Е. В. Кремянской, В. И. Перцу хова. - Краснодар : Кубанский государственный аграрный университет им. И. Т. Трубилина, 2017. -235 с. - Текст : непосредственный.

12. Обзор рынка сельского хозяйства 2018. Исследовательский центр компании «Делойт» в СНГ. - Москва, 2018. - URL: https://www2.deloitte.com/ru/ru/pages/consumer-business/articles/snapshot-of-therussian-agroindustry.html свободный. (дата обращения: 19.11.2019). - Текст : электронный.

13. Poppendieck, M. Lean Software Development : An Agile Toolkit / M. Poppendieck, T. Poppendieck. Publisher : Addison Wesley, 2003. - 184 c. - Текст : электронный.

14. Winston, W. R. Managing the development of large software systems BШЭ/W. R. Winston - URL: https:// www.cs.umd.edu/ basili/publications/journals/J90.pdf свободный. (дата обращения: 19.11.2019). Текст : электронный.

15. Валовый внутренний продукт по источникам доходов // Доступ из справ. системы «ГСК». URL: https://www.gks.ru/free_doc/new_site/vvp/vvp-god/tab33.htm свободный. (дата обращения: 19.11.2019). - Текст : электронный.

16. О производстве и использовании валового внутреннего продукта (ВВП) за 2018 год // Доступ из справ. системы «ГСК». - URL: https://www.gks.ru/bgd/free/B04_03/IssWWW.exe/Stg/d04/61.htm свободный. - (дата обращения: 19.11.2019). - Текст : электронный.

17. Прогноз научно-технологического развития агропромышленного комплекса российской Федерации на период до 2030 года : Основные положения. от 30 марта 2016 г. / ВШЭ. - URL: https://www.hse. ru/news/expertise/201397875.html (дата обращения: 19.11.2019). - Текст : электронный. 


\section{REFERENCES AND INTERNET RESOURCES}

1. Alieva, D. M. Realizatsiya proektnogo podkhoda $\mathrm{v}$ gosudarstvennom upravlenii APK (Implementation of the project approach in the state management of agriculture) / D. M. Alieva // Nauchno-tekhnicheskoe obespechenie agropromyshlennogo kompleksa v realizatsii Gosudarstvennoi programmy razvitiya sel'skogo khozyaistva do 2020 goda : materialy mezhdunarodnoi nauchno-prakticheskoi konferentsii, posvyashchennoi 75-letiyu Kurganskoi GSKhA imeni T.S. Mal'tseva. - Saratov, 2019. - S. 155-158.

2. Bratchenko, S. A. Formirovanie fundamental'nykh upravlencheskikh idei v period stanovleniya kapitalizma kratkii obzor nauchnykh rabot (Formation of fundamental management ideas during the formation of capitalism a brief review of scientific works) / S. A. Bratchenko // Upravlencheskie nauki. - 2018. - T. 8. № 1. - S. 110-118.

3. Gromov, A. I. i dr. Upravlenie biznes-protsessami: sovremennye metody (Business process management: modern methods): kollektivnaia monografiya / A. I. Gromov i dr. - Moskva : Yurait, 2017. - 368 s.

4. Gur'yanova, N. M. i dr. Problemy i osnovnye napravleniya povysheniya effektivnosti funktsionirovaniya APK regiona v usloviyakh globalizatsii i impotozameshcheniya (Problems and main directions of increase of efficiency of functioning of agroindustrial complex of the region in the conditions of globalization and import substitution) / N. M. Gur'yanova i dr. ; pod red. O. A. Stolyarovoi. - Penza : RIO PGAU 2018. - $236 \mathrm{~s}$.

5. Dibirov, A. A. Potentsial integratsii stran EAES v sfere prodovol'stvennogo obespecheniya naseleniya (Potential of integration of the EAEU countries in the sphere of food security of the population) / A. A. Dibirov, E. S. Vouba // Ekonomika novogo mira. - 2017. - № 4 (8). - S. 26-36.

6. Lyasnikov, N. V. Agropromyshlennyi kompleks Rossii i neobkhodimost' obespecheniya prodovol'stvennoi bezopasnosti v usloviyakh mezhdunarodnykh sanktsii (Russia's agro-industrial complex and the need to ensure food security under international sanctions) / N. V. Lyasnikov // Problemy rynochnoi ekonomiki. 2018. - № 2. - S. 19-25.

7. Naidenova, N. V. Ekonomicheskie faktory ogranicheniya rosta rossiiskoi ekonomiki (Economic factors limiting the growth of the Russian economy) / N. V. Naidenova // Vestnik SGYuA. - 2017. - № 1 (114). S. 231-238.

8. Sultygova, M. B. Formirovanie klyuchevykh detirminantov v sisteme ekonomicheskoi bezopasnosti (Formation of key determinants in the system of economic security) / M. B. Sultygova // Vestnik evraziiskoi nauki. - 2018. - T. 10. - № 3. - S. 39.

9. Chizhova, E. N. Istoriya upravlencheskoi mysli (History of management thought) / E. N. Chizhova, I. P. Medvedev. - Belgorod : Izd-vo BGTU, 2018. - 401 s.

10. Zhuchenko, A. A. Sredouluchshayushchie tekhnologii v XXI veke (Environment-improving technologies in the XXI century) / A. A. Zhuchenko // Vestnik Orlovskogo gosudarstvennogo agrarnogo universiteta. 2017. - № 3 (66). - S. 16-26.

11. Problemy i perspektivy povysheniya effektivnosti funktsionirovaniya sveklosakharnogo podkompleksa APK (Problems and prospects of increase of efficiency of functioning of beet sugar subcomplex of agroindustrial complex) / pod red. G. G. Lalayan, E. V. Kremyanskoi, V. I. Pertsukhova. - Krasnodar : Kubanskii gosudarstvennyi agrarnyi universitet im. I.T. Trubilina, 2017. $-235 \mathrm{~s}$.

12. Obzor rynka sel'skogo khozyaistva 2018 (Agriculture market review 2018). Issledovatel'skii tsentr kompanii «Deloit»v SNG. - Moskva, 2018 [Elektronnyi resurs]. - URL: https://www2.deloitte.com/ru/ru/pages/ consumer-business/articles/snapshot-of-the-russian-agroindustry.html svobodnyi. (data obrashcheniya: 19.11.2019).

13. Poppendieck, M. Lean Software Development : An Agile Toolkit / M. Poppendieck, T. Poppendieck. Publisher : Addison Wesley, 2003. - $184 \mathrm{~s}$.

14. Winston W. R. Managing the development of large software systems ВШЭ/ W. R. Winston [Электронный pecypc]. - URL: https://www.cs.umd.edu/ basili/publications/journals/J90.pdf свободный (дата обращения: 19.11.2019).

15. Valovyi vnutrennii produkt po istochnikam dokhodov (Gross domestic product by source of income) // Dostup iz sprav. sistemy «GSK». - URL: https://www.gks.ru/free_doc/new_site/vvp/vvp-god/tab33.htm svobodnyi. (data obrashcheniya: 19.11.2019). 
16. O proizvodstve $\mathrm{i}$ ispol'zovanii valovogo vnutrennego produkta (VVP) za 2018 god (On the production and use of gross domestic product (GDP) for 2018) // Dostup iz sprav. sistemy «GSK». - URL: https://www. gks.ru/bgd/free/B04_03/IssWWW.exe/Stg/d04/61.htm svobodnyi. - (data obrashcheniya: 19.11.2019).

17. Prognoz nauchno-tekhnologicheskogo razvitiya agropromyshlennogo kompleksa rossiiskoi Federatsii na period do 2030 goda (Forecast of scientific and technological development of the agro-industrial complex of the Russian Federation for the period up to 2030) : Osn. Polozheniya. ot 30 marta 2016 g. / VShE [Elektronnyi resurs]. - URL: https://www.hse.ru/news/expertise/201397875.html. (data obrashcheniya: 19.11.2019).

\section{СВЕДЕНИЯ ОБ АВТОРЕ}

Гуринов Андрей Васильевич, аспирант Ставропольского государственного аграрного университета. Е-mail: andriuslt@inbox.ru

\section{INFORMATION ABOUT AUTHOR}

Gurinov Andrej Vasiljevich, Stavropol State Agrarian Univerisity, Chair of Entrepreneurship and the Global Economy. E-mail andriuslt a inbox.ru 